\title{
The Effect of Depressive Emotional State on the Efficacy of Physical Therapy in Patients with Low Back Pain
}

\author{
Fatma Tezel Mayalı ${ }^{1}$, Bengi Oz ${ }^{1}$, Demet Gülpek ${ }^{2}$, Özlem Yoleri ${ }^{1}$, Beyza Taşkın Topaloğlu ${ }^{2}$, \\ Hikmet Koçyiğit ${ }^{1}$ \\ ${ }^{1}$ Ataturk Training And Research Hospital Katip Celebi University Physical Therapy And Rehabilitation Clinic, Izmir/Turkey \\ ${ }^{2}$ Ataturk Training And Research Hospital Katip Celebi University Psyciatry Clinic, Izmir/Turkey
}

Received: 15 April 2016, Accepted: 22 June 2016, Published online: 25 August 2016

(C) Ordu University Institute of Health Sciences, Turkey, 2016

\begin{abstract}
Objective: The aim was to investigate the effect of depressive emotional state on the efficacy of physical therapy in patients with chronic mechanical low back pain (LBP).

Methods: Sixty patients with chronic LBP were included in the study. The patients were evaluated by a psychiatrist according to the Hamilton Depression Rating Scale (HAM-D) and separated into 2 groups regarding the cut off score. Group 1 consisted of 31 patients without depressive emotion while group 2 included 29 patients with depressive emotion. An exercise program consisting of lumbar dynamic stabilization exercises was instructed to all of the patients for 8 weeks. Infrared, ultrasound and TENS were applied to both groups for 15 seance. The pain was evaluated by visual analog scale (VAS), disability and quality of life was evaluated by Oswestry disability index and the Short-Form 36(SF-36) at baseline and 3rd and 8th weeks.

Results: İmprovement at pain severity during ADL, rest and sitting position was found to be significantly higher in group 2 compared to group 1 patients at the 8th week $(\mathrm{p}<0.05)$. Oswestry scores and some subscale of SF-36; physical functioning, general health perception, vitality, mental health scores of group 2 were significantly higher compared to group 1 at baseline and the 8th week $(p<0.05)$. Improvement of Oswestry scores between groups was not significantly different at 8 th week ( $p>0.05)$, but improvement of some SF-36 subscale scores (pain, emotional role functioning, mental health) of groups significantly lower in group 2 compared to group 1 at the 8 th weeks $(\mathrm{p}<0.05)$.

Conclusions: Patients with chronic LBP and a depressive emotional state are inclined to have more disability and poorer quality of life, while physical therapy and exercises yield to less improvement in scores of pain and some subscales of the SF-36 in these patients than those without depressive affect.
\end{abstract}

Key words: Chronic low back pain, depression, physical therapy

Address for correspondence/reprints:

\section{Bengi Öz}

Telephone number: +90 5327058015

E-mail: bengiates@yahoo.com.tr

DOI: $10.19127 / \mathrm{mbsjohs} .74107$

This article was presented at World Congress of the International Society of Physical and Rehabilitation Medicine and published as an abstract in the journal of PMR.

\section{Introduction}

Low back pain (LBP) is a widespread health disorder that occurs during the lifetime of $65-80 \%$ of the general population. Although the prognosis is usually good, the management of disability that is associated with LBP presents a challenging problem (Felson 1997; Weinstein et al. 2005). The course of patients with acute mechanical back pain is one of gradual improvement over a 6-week period with total recovery in almost $90 \%$, however pain persists for more than 3 months in $7-10 \%$ and develops a chronic character causing serious work 
absenteeism and economic loss (Andersson, 1999; Velbaunt et al., 2003; Weinstein et al., 2005). The treatment of LBP initiates with controlled physical activity, prescription of non-steroidal antiinflamatory drugs (NSAIDs) and myorelaxants, and lumbar supports. If pain does not resolve within a few weeks, a multidisciplinary approach becomes essential and exercises, physical therapy modalities, mobilization, manipulation, acupuncture, and behavioral therapy are utilized as adjunctive procedures (Van Middelkoop et al, 2011; Silvemark et al., 2014).

The treatment of chronic LBP is difficult and longstanding pain causes disability and creates both social and individual restrictions (Andersson, 1999). Although research has demonstrated that physical therapy for back pain can be effective and widely accepted as useful in combination with exercises in coping with pain and providing functional recovery, overall treatment effect sizes have tended to be small, regardless of the treatment modality used (Keller et al 2007; Van Middelkoop et al., 2011; Alkan et al., 2011;). It is argued that one explanation for the small effect sizes might be individual patient variability, both in terms of general prognosis and in terms of response to a specific intervention (Jonathan et al., 2011).

The prevalence of depression was found to be $32.1 \%$ in chronic LBP patients and patients with depression had higher pain intensity, greater fear of movement and poorer quality of life (Antunes et al., 2013).

The aim of this study was to compare the response of patients with depressive affect with that of patients without depressive affect to a treatment program of physical therapy modalities and exercises. As far as we know, our study is unique in respect to its design and purpose.

\section{Methods}

Seventy five patients admitted to our clinic aged between 30-65 years with chronic LBP for at least 3 months were included in this study. Four of 75 patients diagnosed as major depression by a psychiatrist and had begun antidepressant treatment which would affect the study results were excluded from the study. Eleven patients out of 75 patients were either dropouts or inadequate participation to the physical therapy and/or home exercise program. Sixty patients were completed the study. Neurological deficit, red flags, history of lumbar operation, pregnancy, compression fracture, hip pathology, any contraindication for physical therapy (infection, inflammation or malignancy), exercise intolerance, spinal instability (Spondylolisthesis, spondylolysis, congenital deformity, scoliosis), fibromyalgia, major depression, drug usage for depression were the exclusion criteria of the study.

The patients were evaluated by a psychiatrist according to the Hamilton Depression Rating Scale (HAM-D) and separated into 2 groups regarding the cut off score (normal<7; depressive affect $>7$ ) (Akdemir et al., 1996). Group 1 consisted of 31 patients without depressive affect while group 2 included 29 patients with depressive affect. Physical therapists providing care were blinded to the grouping of each patient. Both groups were assigned core stabilization exercises and physical therapy for 3 weeks under physical therapist supervision and continued to perform exercises up to 8th week as home programme. The core stabilization exercises were performed 5 times a week. Compliance with home exercise programme was monitorized by a daily check chart. Patients less than three days a week participatine to the exercise program were excluded from the study.

The program included flexibility and strengthening exercises. For flexibility; hip flexors, gluteals and hamstrings were stretched for 20 seconds, 3 times in each session. For strengthening; a) supine abdominal draw in, b) prone bridging on elbows, c) quadruped opposite arm/leg, d) supine butt lift with arms at side 6 weeks, e) prone Cobra's exercises were performed, each twice a day with 5 to 10 repetitions. Superficial heating with hot packs was applied to the low back region for 20 minutes. The patients also received ultrasound (US) diathermy using an ultrasound device (Chattanooga, Tennessee, USA) that operated at 1 $\mathrm{MHz}$ frequency and $2 \mathrm{~W} / \mathrm{cm} 2$ intensity. The treatment duration was 7 minutes. Finally, transcutaneous electrical nerve stimulation (TENS); $50-100 \mathrm{~Hz}$ by means of conventional method was applied for 30 minutes. The physical therapy sessions were applied five times a week for 3 weeks. Patients were allowed to only etafonamat $800 \mathrm{mg} /$ day for pain management if necessary.

Age, sex, weight, height and occupation of each patient were noted at baseline evaluation. Body mass index was calculated. Pain duration, existence of radicular pain and paresthesia and lumbar MRI findings were recorded. Both groups were assessed for pain, disability and quality of life before and at 
the 3rd week and 8th week follow-up. Low back pain severity during activities of daily living (ADL), at rest and sitting position was assessed by visual analogue scale (VAS, 0: no pain, $10 \mathrm{~cm}$ : severe pain) (Dixon and Bird, 1981). Oswestry disability index was used for disability assessment (Fairbank and Pynsent, 2000). Finally, quality of life of the patients was assessed by Short-Form 36 (SF-36) (Kocyigit H et al., 2001).

\section{Statistical evaluation}

Data were analyzed using SPSS-15.0 for Windows statistical package. The suitability of the normal distribution of the data was analyzed by normality with plots test. Data without normal distributed were compared by Mann-Whitney test, while data with normal distribution were compared by student $\mathrm{t}$ test between groups.

Data about the sociodemographic and clinical characteristics of the groups with nominal values were compared by Chi-square test. The groups were compared as to their response to treatment by ANOVA repeated measures analysis. If baseline comparisons of groups were statistically significantly different, covariate analysis was done. Value of significance was accepted as $p<0.05$ for all tests.

\section{Results}

Thirty three (44\%) out of 75 patients with chronic LBP had depressive emotional state and 4 of them $(5.3 \%)$ had major depression. Most of the patients with depressive affect were female $(75.9 \%)$ (Table 1). Demographic data of groups were given in table 1 . Both groups had similar pain duration, age, sex, occupation ratios, and weight, height and body mass index (BMI) values. Groups did not differ in existence of radicular pain and lumbar MRI findings, except symptom of paresthesia (Table 2).

Improvement at pain severity during ADL, rest and sitting position was found to be significantly higher in group 2 compared to group 1 patients at the 8th week $(\mathrm{p}<0.05)$. Both groups showed significant improvement in all VAS scores compared to baseline (except pain during sitting position in group 2 at the 8 th week) at the $3 \mathrm{rd}$ and 8th weeks $(\mathrm{p}<0.05)$ (Table 3$)$. Oswestry scores of group 2 were significantly higher compared to group 1 at baseline and the 8th week $(\mathrm{p}<0.05)$. When covariance analysis was done for the baseline values, improvement of oswestry scores between groups was not significantly different at 8 th week (p>0.05). Improvement within groups was achieved only in group 2 at the 3 rd week, but only group 1 had significant improvement at the 8th week $(p<0.05)$ (Table 4). Some SF-36 subscale scores; pain and emotional role functioning of groups were statistically similar at baseline, and significant improvement was achieved at these scores in group 2 compared to group 1 at the 8th weeks $(\mathrm{p}<0.05)$. Improvement of physical role functioning and social role scores of SF- 36 were not differing between groups at 8 th week. Other subscales of SF36 (physical functioning, general health perception, vitality, mental health) evaluated at baseline, and 8th weeks were all statistically lower in group 2 patients $(\mathrm{p}<0.05)$. When covariance analysis was done for the baseline values of these subparameters; improvement of mental health scores was statistically significantly different between groups at the 8th week. But, improvement of social role, physical functioning, general health perception and vitality were not differing between groups at 8th week (Table 5). Significant improvement within groups was achieved in both groups in pain and physical role items at the 3rd week, but only group 1 had significant improvement in physical functioning at the 3rd week and also pain, physical role functioning scores at the 8 th week $(\mathrm{p}<0.05)$.

\section{Discussion}

The prevalence of depressive emotional state was found to be $44 \%$ in chronic LBP patients and $5.3 \%$ of them had major depression. Majority of patients with depressive affect were found to be female. Physical role functioning, general health, vitality and mental health scores were found to be lower in patients with chronic LBP and depressive affect. Oswestry scores that evaluate functional disability associated with back pain have also been found to be poorer in these patients. Longstanding pain leads to impairment in physical activity and quality of life (Bigos et al., 2001). Our study has demonstrated that quality of life deteriorates to a greater extent when depressive affect accompanies pain. The prominent difference in quality of life of patients with similar clinical and radiological findings and pain intensity supports the fact that depressive affect increases disability significantly. While the prevalence of depression is $5-8 \%$ in the general population, the prevalence ranges between 22 and $78 \%$ in patients with chronic pain (Haythornthwaite et al., 1991). 
Table 1: Comparison of Demographic Data of Groups

\begin{tabular}{|c|c|c|c|c|}
\hline & & Group 1 (n:31) & Group 2 (n:29) & $\mathrm{P}$ value ${ }^{*} \dagger$ \\
\hline \multirow[t]{2}{*}{ Sex } & $\operatorname{Men}(\%)$ & $15(48.4)$ & $7(24.1)$ & \multirow[t]{2}{*}{$0.051^{*}$} \\
\hline & Women (\%) & $16(51.6)$ & $22(75.9)$ & \\
\hline Age(year) & & $46.16 \pm 9.89$ & $46.65 \pm 8.19$ & $0.941 \dagger$ \\
\hline Height $(\mathrm{cm})$ & & $165.55 \pm 9.68$ & $163.69 \pm 10.2$ & $0.688 \dagger$ \\
\hline Weight(kg) & & $77.7 \pm 13.78$ & $76.13 \pm 13.85$ & $0.568 \dagger$ \\
\hline $\operatorname{BMI}\left(\mathrm{kg} / \mathrm{m}^{2}\right)$ & & $28.35 \pm 4.54$ & $28.56 \pm 5.48$ & $0.684 \dagger$ \\
\hline Pain duration(month) & & $65.32 \pm 75.80$ & $74.62 \pm 67.53$ & $0.619 \dagger$ \\
\hline \multicolumn{5}{|l|}{ Occupation } \\
\hline House women $(\%)$ & & $14(45.2)$ & $17(58.6)$ & \multirow{5}{*}{$0.292 *$} \\
\hline Hard worker(\%) & & $9(29)$ & $9(31)$ & \\
\hline Desk job $(\%)$ & & $3(9.7)$ & 0 & \\
\hline Retired $(\%)$ & & $5(16.1)$ & $3(10.3)$ & \\
\hline Unemployed(\%) & & 0 & 0 & \\
\hline
\end{tabular}

*Chi-square and †mann- whitney test

Table 2. Comparison of Clinical Symptoms and Lumbar MRI Findings of Groups

\begin{tabular}{lccc}
\hline & Group 1(n)(\%) & Group 2(n)(\%) & P value* $^{*}$ \\
\hline Pain radiating to leg (+/-) & $27(87.1) / 4(12.9)$ & $24(82.8) / 5(17.2)$ & 0.638 \\
Parasthesia (+/-) & $19(61.3) / 12(38.7)$ & $25(86.2) / 4(13.8)$ & 0.029 \\
\hline Disc pathology & $4(12.9)$ & $2(6.9)$ & 0.216 \\
Bulging & $25(80.6)$ & $22(75.9)$ & \\
Protrusion & $1(3.2)$ & $5(17.2)$ & 0.098 \\
Extrusion & $1(3.2)$ & 0 & 0.697 \\
Secestration & & & \\
\hline Root compression $(+/-)$ & $15(48.4) / 16(51.6)$ & $8(27.6) / 21(72.4)$ & \\
Stenosis $(+/-)$ & $3(9.7) / 28(90.3)$ & $2(6.9) / 27(93.1)$ & \\
\hline
\end{tabular}

*Chi-square test

Table 3: Comparison of Pain Intensity at Baseline, 3rd and 8th Weeks Between and within Groups

\begin{tabular}{|c|c|c|c|c|}
\hline VAS $(0-10 \mathrm{~cm})$ & & Group 1 & Group 2 & $\mathrm{P}$ value \\
\hline \multirow[t]{5}{*}{ Pain during ADL } & baseline & $6.64 \pm 1.40$ & $7.2 \pm 1.49$ & $0.139 \dagger$ \\
\hline & 3.week & $3.22 \pm 1.83$ & $4.58 \pm 2.19$ & $0.000 *$ \\
\hline & & $\mathrm{P}<0.001$ & $\mathrm{P}<0.001$ & \\
\hline & 8.week & $3.54 \pm 1.52$ & $5.65 \pm 2.07$ & \\
\hline & & $\mathrm{P}<0.001$ & $\mathrm{P}=0.001$ & \\
\hline \multirow[t]{5}{*}{ Pain during rest } & baseline & $2.93 \pm 2.01$ & $3.48 \pm 2.18$ & $0.317 \dagger$ \\
\hline & 3.week & $0.96 \pm 1.53$ & $1.44 \pm 1.50$ & $0,039 *$ \\
\hline & & $\mathrm{P}<0,001$ & $\mathrm{P}<0,001$ & \\
\hline & 8.week & $0.77 \pm 1.52$ & $2.13 \pm 1.84$ & \\
\hline & & $\mathrm{P}<0.001$ & $\mathrm{P}<0.001$ & \\
\hline \multirow[t]{5}{*}{ Pain during sitting } & baseline & $3.74 \pm 1.56$ & $4.10 \pm 2.05$ & $0.446 \dagger$ \\
\hline & 3.week & $2.12 \pm 1.54$ & $2.82 \pm 1.81$ & \\
\hline & & $\mathrm{P}<0.001$ & $\mathrm{P}=0.001$ & $0.000 *$ \\
\hline & 8.week & $1.93 \pm 1.59$ & $3.65 \pm 2.14$ & \\
\hline & & $\mathrm{P}<0.001$ & $\mathrm{P}=0.196$ & \\
\hline
\end{tabular}

*ANOVA repeated measures analysis and student $\mathrm{t}$ test $\dagger$

Table 4: Comparison of Oswestry Scores at Baseline, 3rd and 8th Weeks Between and within Groups

\begin{tabular}{llll}
\hline Oswestry scores & Group 1 & Group 2 & P value \\
Baseline & $46.38 \pm 13.99$ & $58.48 \pm 15.34$ & $0.002 \dagger$ \\
3.week & $39.00 \pm 21.06$ & $48.34 \pm 21.67$ & \\
& $* \mathrm{P}=0.051$ & $* \mathrm{P}=0.003$ & $0.299 *$ \\
8.week & $38.19 \pm 17.49$ & $55.75 \pm 20.59$ & \\
& $* \mathrm{P}=0.012$ & $* \mathrm{P}=0.349$ & \\
\hline
\end{tabular}

ANOVA repeated measures analysis with covariate anaysis*, mann-whitney test 
The concurrence of chronic pain and psychiatric diagnosis has been reported as $16.9 \%$ in an epidemiologic study in England (Benjamin et al., 2000). The interaction of pain intensity, duration, and disability with depression, anxiety and psychological stress has been reported in various studies (Bigos et al., 2001). Brain et al. (2003) reported that the prevalence of pain in depressed cohorts and depression in pain cohorts are higher than when these conditions are individually examined. Depression in patients with pain is associated with more complaint of pain and greater impairment (Bair et al., 2003).

It was also stated in the available literature that a clear link exists between psychological variables (stress, distress, or anxiety as well as mood and emotions, cognitive functioning, and pain behavior) and neck and back pain (Bair et al., 2003; Bener et al., 2013). Chronic LBP has been shownto be strongly related with psychosocial factors and depression is seen in $30-40 \%$ of patients (Turhanoglu, 2011). Demyttenaere et al. (2007) suggested that mental disorders (anxiety disorders and major depression and dysthymia) were more common among persons with back/neck pain than among persons without. Michalski et al. (2006) have reported that in patients with chronic LBP anxiety and depression are related with age and women tend to have more anxiety than men and depression is more common than anxiety. It is believed that the restriction of daily activities along with continuous perception of pain produces a tendency to depression in patients with LBP (Linton, 2000).

The influence of psychological factors also seems to be important in the transition from acute to chronic low back pain (Linton, 2000). It was known that depression and pain share biological pathways and neurotransmitters, which has implications for the treatment of both concurrently (Bair et al., 2003).

Loss of physical capacities, or deconditioning, occurs as a consequence of persistent activity restrictions. These physical impairments result in disability, or decreased ability to engage in activities of daily living (Cohen, 2002). It has been found that certain symptoms of depression (especially, feeling that everything requires an effort, low energy) were more common among patients with co-occurring pain than in depressed patients without pain (Korff et al., 1996). In another study conducted by Snekkevik et al. (2014) usculoskeletal pain and depression have been found to be independently associated with substantial fatigue. Deconditioning as a result of both pain and depression results in disability. Work absenteeism has been shown to be twice more frequent in patients with pain and depression than those with only depression (Demyttenaere et al., 2006). According to Häuser et al (2014); age, widespread pain, and depression are independent predictors of disability as shown in their study comparing patients with disabling and nondisabling chronic LBP. Multivariate analyses have shown that the unique predictors of disability for LBP patients were pain and depression (Bean et al., 2014).

The evidence from randomised controlled trials has demonstrated that exercise therapy is effective in reducing pain and improving function in the treatment of chronic LBP (Middelkoop et al., 2010). It is also suggested thatactivity and active involvement in treatment are particularly important with chronic pain patients who are depressed (Dworkin et al., 1986).

Our results are in concordance with the evidence in previous studies. We prescribed dynamic lumbar core exercises and physical therapy modalities to both groups. Improvement within groups was achieved in pain, disability and physical role of both groups at the 3rd week, but only group 1 had significant improvement in these parameters and also emotional role at the 8th week.

Durmus et al. (2014) have reported that exercise therapy resulted in significant improvement in pain, disability, muscle strength, endurance, SF-36, and depression in patients with chronic low back pain. In a study comparing 3 different treatment regimens in chronic LBP patients, the first group was instructed in home exercise program, the second was given TENS, local heat and therapeutic ultrasound besides a home exercise program and the last group did aerobic exercises with a treadmill three days a week and also received a home exercise program. Reduction of pain was achieved in all group sat short term but improvement in the emotional state and functioning was seen only in the group that was treated with physical therapy modalities and home exercise program (Koldas et al., 2008).However, improvement in pain intensity and subparameters of SF-36 such as pain, emotional role functioning and mental health were better at the 8th week follow up in patients without depressive affect. We have demonstrated that besides impairment of quality of life, poor response to treatment was also observed in chronic LBP patients with depressive affect. Influence of having depressive state was especially on the improvement of pain and emotional state of the patients. 
Disability and physical capacity of the patients after physical therapy were not found to be effected from the depressive state of the patients.

There have been few systematic comparisons of chronic pain patients with and without depression regarding their response to treatment. In contrast to our findings, one of them reported (Dworkin et al., 1986) that depressed and non-depressed chronic pain patients were found to be quite similar with respect to demographic, pain-related, and treatment response variables. Another single blind prospective cohort study based on patients with chronic low back pain who completed a 4-week multimodal rehabilitation program showed that depressive symptoms demonstrated no predictive value for pain reduction (Michaelson et al., 2004).

However, Melloh M et al (2014) suggested that better mental health (subscale of SF-36) predicted improved outcome in an individually designed exercise therapy program for chronic LBP. Also, adherence to the exercise program almost doubled the probability of a favorable outcome. It was also shown (Melloh et al., 2013) that depression was associated with LBP especially after 6 weeks and course of recovery was slower in depressive patients with acute back pain.

According to Schmerz et al. (2013) multiple target approach to reduce pain, pain-related fear and avoidance behavior and also depressive symptoms should be considered in the treatment of chronic LBP. Self-efficacy and fear avoidance beliefs in chronic LBP patients seemed to be associated with depression, disability, and fatigue (Moraes Vieira et al., 2014). Turner et al. (2007) have identified the prognostic factors of LBP outcome as a higher level of depressive symptoms, nonspecific physical problems, rumination, catastrophizing, and stress at baseline.

\section{Conclusion}

Our study has shown that patients with chronic LBP and a depressive emotional state are inclined to have more disability and poorer quality of life, while physical therapy and exercises yield to less improvement in pain and some items of quality of life in SF-36 in these patients than those without depressive affect. Evaluation of emotional state in patients with chronic low back pain before initiation of physical therapy seems to be useful in the prediction of efficacy of treatment.

Though association of chronic pain and depression has been a known fact, the influence of depressive effect on treatment outcome is still an open field for investigation. Our study demonstrates the need for new studies concerning the relationship of response to treatment with depressive emotional state.

Informed Consent: Ethics committee approval was received fort this study from Clinic Research Ethics Committee of Izmir Katip Çelebi University. Peer-review: Externally peer-reviewed.

Author Contributions: Concept-OB, TMF, Design-OB, GD, TMF,Supervision-KH, MaterialsTMF,Data collection and/or processing- GD, TMF, TTB,Analysis and/or Interpretation-OB,LiteratureTMF, OB,Writing-TMF, OB, YO,Critical Review$\mathrm{KH}, \mathrm{OB}$.

Conflict of Interest: No conflict of interest was declared by the authors.

Financial Disclosure: The authors declared that this study hasn't received any financial support.

\section{References}

Akdemir A, Örsel S, Dag I, Türkcapar H, Iscan N, Ozbay H. Clinical use and the reliability and validtyy Of the Turkish version of the Hamilton Depression Rating Scale (HDRS). 3P J. 1996; 4: 251-9.

Alkan H, Ardiç F. The role of medication and physical therapy interventions in the management of mechanical low back pain. J PM \&R-Special Topics 2011; 4: 75-84.

Andersson GB. Epidemiological features of chronic low-back pain. Lancet. 1999; 354: 1-585.

Antunes RS, de Macedo BG, AmaralTda S, Gomes Hde A, Pereira LSM, Rocha FL. Pain, kinesiophobia and quality of life in chronic low back pain and depression.Acta Ortop Bras 2013;21:27-9.

Bair MJ, Robinson RL, Katon W. Depression and pain comorbidity: a literature review. Arch Intern Med. 2003; 163: 2433-45.

Bean DJ, Johnson MH, Kydd RR. Relationships between psychological factors, pain and disability in complex regional pain syndrome and low back pain. Clin J Pain 2014; 30: 647-53. 
Bener A, Verjee M, Dafeeah EE, Falah O, AlJuhaishi T, Schlogl J, et al. Psychological factors: anxiety, depression, and somatization symptoms in low back pain patients. J Pain Res 2013; 6: 95-101.

Benjamin S, Morris S, McBeth J, Macfarlane GJ, Silman AJ. The association between chronic widespread pain and mental disorder: a population based study. Arthritis Rheum 2000; 43: 561-7.

Bigos JS, Müller G: Primary care approach to acute and chronic back problems: definitions and care. Bonica's management of pain. Edited by Looser JD. Lippincott Wiliams\& Wilkins, Philadelphia, 2001, pp. 1509-28.

Cecchi F, Pasquini G, Paperini A, Boni R, Castagnoli C, Pistritto S, Macchi C. Predictors of response to exercise therapy for chronic low back pain: result of a prospective study with one year follow-up. Eur J PhysRehabil Med 2014; 50: $143-51$.

Cohen I, Rainville J. Aggressive Exercise as Treatment for Chronic Low Back Pain. Sports Med 2002; 32: 75-82.

Demyttenaere K, Bonnewyn A, Bruffaerts R. Comorbid painful physical symptoms and depression: prevalance, work loss, and help seeking. J Affect Disord 2006; 92: 185-93.

Demyttenaere K, Bruffaerts R, Lee S, Posada-Villa J, Kovess V, Angermeyer MC, et al. Mental disorders among persons with chronic back or neck pain: results from the World Mental Health Surveys. Pain. 2007; 129: 332-42.

Dixon JS, Bird HA. Reproducibility along a $10-\mathrm{cm}$ vertical visual analogue scale. Ann Rheum Dis 1981; 40: 87-9,

Durmus D, Unal M, Kuru O. How effective a modified exercise program on its own or with back school in chronic low back pain? A randomized-controlled clinical trial. J Back Musculo skelet Rehabil. 2014; 27(4): 553-61.

Dworkin RH, Richlin DM, Handlin DS, Brand L. Predicting treatment response in depressed and non-depressed chronic pain patients. Pain. 1986; 24: 343-53.
Fairbank JC, Pynsent P. The Oswestry Disability Index. Spine. 2000; 25: 2940-52.

Felson DT. Epidemiology of the rheumatic diseases.Koopman WJ, McCarty DJ, editors.Arthritis and Allied Conditions. Baltimore: Williams \& Wilkins; 1997. p. 3-34.

Häuser W, Schmutzer G, Brähler E, Schiltenwolf M, Hilbert A. The Impact of body weight and depression on low back pain in a representative population sample. Pain Med. 2014; 15: 131627.

Haythornthwaite JA, Sieber WJ, Kerns RD. Depression and the chronic pain experience. Pain. 1991; 46: 177-84.

Jonathan C. Hill and Julie M. Fritz Psychosocial Influences on Low Back Pain, Disability, and Response to Treatment. Physical Therapy 2011; 91: 712-21.

Keller A, Hayden J, Bombardier C, et al. Effect sizes of non-surgical treatments of non-specific low-back pain. Eur Spine J. 2007; 16(11): 177688.

Kocyigit H, Aydemir O, Olmez N, Memis A. SF36'nınTürkçeiçingüvenilirliğivegeçerliliği. İlaçveTedaviDergisi 1999; 12: 102-6.

Koldas Dogan S, Sonel Tur B, Kurtais Y, Atay MB. Comparison of three different approaches in the treatment of chronic low back pain.Clin Rheumatol 2008; 27(7): 873-81.

Korff von M., Simon G. The relationship between pain and depression. Br J Psychiatry. 1996; 168: $101-8$

Linton SJ. A review of psychological risk factors in back and neck pain. Spine 2000; 25: 1145-56.

Melloh M, Elfering A, Käser A, Salathé CR, Barz $\mathrm{T}$, Aghayev E, et al. Depression impacts the course of recovery in patients with acute lowback pain. Behav Med 2013; 39: 80-9.

Michaelson P, Sjölander P, Johansson H. Factors predicting pain reduction in chronic back and neck pain after multimodal treatment. Clin $\mathbf{J}$ Pain 2004; 20: 447-54.

Michalski D, Hinz A. Anxiety and depression in chronic back pain patients: effects on beliefs of control and muscular capasity. Psychother Psychosom Med Psychol 2006; 56: 30-8.

Middelkoop M, Rubinstein SM, Verhagen AP, Ostelo RW, Koes BW, Tulder MW. Exercise therapy for chronic nonspecific low-back pain. Best Pract Res Clin Rheumatol. 2010; 24: 193204. 
Moraes Vieira EB, Salvetti GM, Damiani LP, PimentaCAM. Self-Efficacy and Fear Avoidance Beliefs in Chronic Low Back Pain Patients: Coexistence and Associated Factors. Pain ManagNurs 2014; 15(2): 77.

Seekatz B, Meng K, Faller H. Depressivity as mediator in the fear-avoidance model: a path analysis investigation of patients with chronic back pain. Schmerz 2013; 27: 612-8.

Silvemark A, Källmén H, Molander C. Improved life satisfaction and pain reduction: Follow-up of a 5-week multidisciplinary long-term pain rehabilitation programme. Ups J Med Sci 2014; 119: 278-86.

Snekkevik H, Eriksen HR, Tangen T, Chalder T, Reme SE. Fatigue and Depression in Sick-Listed Chronic Low Back Pain Patients. Pain Med 2014; 15: 1163-70.

Turhanoglu AD. Chronic low back pain. J PM \&RSpecial Topics 2011; 4: 117-22.

Turner JA, Holtzman S, Mancl L. Mediators, moderators, and predictors of therapeutic change in cognitive-behavioral therapy for chronic pain. Pain. 2007; 127: 276-86.

Van Middelkoop M, Rubinstein SM, Kuijpers T, Verhagen AP, Ostelo R, Koes BW, et al. A systematic review on the effectiveness of physical and rehabilitation interventions for chronic non-specific low back pain.Eur Spine J 2011; 20: 19-39.

Velbaunt JA, Seeelen HA, Vlayen JW, van de Heiden GJ, Heuts PH, Pons K et al. Disuse and deconditioning in chronic low back pain: concepts and hypotheses on contributing mechanisms. Eur J Pain. 2003; 7: 9-21.

Weinstein SM, Herring SA, Standaert CJ. Low back pain Delisa J, editor. Physical Medicine and Rehabilitation; principles and practice. Philadelphia: Lippincott Wiliams\& Wilkins. 2005. p. 653-75. 